Relations industrielles

Industrial Relations

\title{
Papers on Absenteism, by K.N. Vaid, Shri ram Centre for Industrial Relations, India, 1967, 109 pp.
}

\section{Laurent Bélanger}

Volume 23, numéro 4, 1968

URI : https://id.erudit.org/iderudit/027970ar

DOI : https://doi.org/10.7202/027970ar

Aller au sommaire du numéro

Éditeur(s)

Département des relations industrielles de l'Université Laval

ISSN

0034-379X (imprimé)

1703-8138 (numérique)

Découvrir la revue

Citer ce compte rendu

Bélanger, L. (1968). Compte rendu de [Papers on Absenteism, by K.N. Vaid, Shri ram Centre for Industrial Relations, India, 1967, 109 pp.] Relations industrielles / Industrial Relations, 23(4), 704-704. https://doi.org/10.7202/027970ar

Tous droits réservés @ C Département des relations industrielles de l'Universite Laval, 1968
Ce document est protégé par la loi sur le droit d'auteur. L’utilisation des services d'Érudit (y compris la reproduction) est assujettie à sa politique d'utilisation que vous pouvez consulter en ligne.

https://apropos.erudit.org/fr/usagers/politique-dutilisation/ 
Papers on Absenteism, by K.N. Vaid, Shri Rom Centre for Industrial Relations, India, 1967, 109 pp.

Au moment où les conditions physiques de travail, les soins médicaux et les revenus s'améliorent, on devrait s'attendre à une diminution des absences dans les entreprises industrielles et les organismes publics. De fait, il appert que le taux d'absentéisme est moins élevé que dans le passé. Cependant, cette baisse ne semble pas se manifester dans les entreprises de l'Inde, en particulier, dans l'industrie du textile. C'est là la raison qui a incité K.N. Vaid et le Centre Shri Ram à entreprendre des études sur l'absentéisme industriel et les facteurs psycho-sociologiques qui peuvent l'expliquer.

Le volume est une collection de quatre articles déjà publiés dans une revue spécialisée en relations industrielles. Les formules utilisées pour calculer le taux d'absentéisme diffèrent radicalement de celles présentées dans les meilleurs volumes en administration du personnel. En fait, l'auteur utilise quatre formules différentes pour les fins de son analyse.

Un dépouillement préliminaire des données permet de conclure qu'un petit groupe d'individus s'absentant de façon chronique fait gonfler le taux d'absence. Les procédures et les règlements concernant l'obtention des permissions de s'absenter constituent un autre déterminant de l'absentéisme.

Pour connaitre les facteurs psycho-sociologiques qui peuvent influencer la décision de s'absenter de son travail, on a construit et administré un questionnaire d'attitudes ò deux groupes différents de travailleurs: ceux qui s'absentent régulièrement et ceux qui sont assidus au travail. L'étude comparative des données montre que les travailleurs qui s'absentent régulièrement partagent moins les objectifs de l'entreprise, sont moins intégrés à leur groupe de travail, sont moins satisfaits de la supervision que ceux qui sont assidus ou travail.

Les causes plus profondes de l'absentéisme sont ajourées par une série d'entrevues auprès de ceux qui s'absentent régulièrement. Le contenu des entrevues a permis au chercheur d'établir cina profils de travailleurs qui s'absentent de façon chronique.

1.-L'entrepreneur: ce type très énergique et original dans ses idées est prêt à assumer des tôches directoriales que l'entreprise ne peut lui offrir.
2.-Le «status seeker »: ce type est un mécontent qui constate le décalage existant entre le statut dont il jouit dans l'entreprise et le standing qu'il croit que la société lu: attribue.

3-- "L'épicurien»: c'est le type qui re cherche un statut social et un revenu élevé mais n'est pas prêt à fournir l'effort néces. saire pour combler ses aspirations.

4.-Le « family man »: c'est le type qui est préoccupé par les problèmies de sa fo. mille au point où il se sent obligé de s'absenter de son travail pour assurer une présence au foyer.

5.-Le type âgé et malade: ce dernier s'absente pour des raisons de maladie chrnnique ou encore à cause d'une constitution psysique débile.

On peut reprocher ò l'auteur le choix des termes pour qualifier le genre de travoilleurs qui s'absentent régulièrement. On peut trouver fastidieux la lecture de nomb.ix tableaux qui apparaissent dans son dernier article. Cependant, c'est un travail de recherche que doivent lire les préposés au personnel dans les entreprises; les étudionts et professeurs en relations industrielles pour les raisons suivantes: a) la démarche utilisée est rigoureuse et elle s'accompagne d'un appareil statistique très simple, facile is saisir; b) les résultats de la recherche peuvent servir de fondements solides à l'élebnration d'une politique d'embauche et de formation du personnel; c) la bibliogrophie imposante qui opparaît à la fin du volume contient les meilleurs ouvrages publiés $5 \mathrm{Jr}$ l'absentéisme depuis plusieurs années

\section{Lourent BELANGER}

\section{Executive Compensation in Large Industrial} Corporation, by Wilbur $\mathrm{G}$. Lewellen, $\mathrm{Na}$ tional Bureau of Economic Resecrch, Columbia University Press, New-York, 1968, 371 pages.

Ce n'est pas tous les jours qu'une itide scientifique nous permet d'entrer dans les niveaux supérieurs de l'administration de: grandes corporations. Celle-ci le fait pour étudier d'une part la rémunération, d'cutre part les différentes formes de compensation pour les directeurs de compagnies. En effet, l'étude de Lewellen a porté sur 250 directeurs de compagnies, soit $5 \mathrm{mem}$ bres de l'exécutif de 50 grandes firmes 